\title{
Avaliação do módulo da aceleração da gravidade com Arduino ${ }^{+*}$
}

\author{
Judismar Tadeu Guaitolini Junior ${ }^{l}$ \\ Centro Brasileiro de Pesquisas Físicas \\ Rio de Janeiro - RJ \\ Gabryel Silva Ramos ${ }^{2}$ \\ Samir Lacerda da Silva ${ }^{3}$ \\ Aline Costalonga Gama ${ }^{4}$ \\ Instituto Federal de Educação, Ciência e Tecnologia do Espírito Santo \\ Campus Vitória \\ Vitória - ES
}

\section{Resumo}

Nesse trabalho, utilizamos a plataforma de hardware livre Arduino para automatizar o processo de coleta de dados no movimento de queda de um objeto, em experimento capaz de fornecer o módulo da aceleração da gravidade local com boa precisão. A partir de sensores posicionados em alturas conhecidas, coletamos os intervalos de tempo gastos por uma esfera para percorrer diferentes distâncias verticais, sendo sua aceleração determinada através da análise de ajuste linear da curva de variação de altura por intervalo de tempo versus intervalo de tempo, onde o dobro da inclinação da reta média corresponde ao módulo local $g$ da aceleração da gravidade. Em virtude das condições de lançamento, os efeitos da resistência do ar não foram considerados na obtenção de g, de modo que consideramos ser esse um movimento de queda livre como boa aproximação. $O$ instrumento desenvolvido nos permitiu obter o valor médio de $g$ diferindo em apenas $1 \%$ do valor encontrado na literatura, mostrando que

\footnotetext{
Module evaluation of the acceleration due to gravity with Arduino

* Recebido: dezembro de 2015. Aceito: abril de 2016.

1 E-mail: jguaitolini@ifes.edu.br

2 E-mail: gabryelsr@gmail.com

3 E-mail: samir.lacerda@ifes.edu.br

4 E-mail: agama@ifes.edu.br
} 
o Arduino é uma ferramenta interessante para aquisição de dados e automatização de experimentos de Física. Reforçamos nesse trabalho a importância da utilização das novas tecnologias no ensino de Ciências, em especial de Física.

Palavras-chave: Arduino; Queda livre; Física Experimental; Novas tecnologias; Ensino de Física.

\begin{abstract}
In this work, we will use the free hardware platform Arduino to automate the experimental process of the free-fall motion of a body, with good accuracy. From sensors positioned at known heights, we analyzed the time interval for a ball to go through diferente vertical distances. The ball acceleration was determined by the linear analysis on height variation over time interval versus time interval, in which the double slope corresponds to the local module g. By virtue of launch conditions, the effects of air resistance were negligible to calculate $g$. Thus, we consider it as a free-fall motion. The instrument developed allowed us to obtain the average value of $g$ differing in only $1 \%$ of the value found in the literature, this shows that the Arduino is an interesting tool for data acquisitionand automation of physics experiments. We emphasize in this paper the importance of using new Technologies in the teaching of Sciences, especially Physics.
\end{abstract}

Keywords: Arduino; Free-fall motion; Experimental Physics; New technologies; Physics teaching.

\title{
I. Introdução
}

A utilização de novas tecnologias no ensino de Física (GELAMO, 2012; LIMA; RAPPOPORT, 2009) deve ser amplamente incentivada nas escolas de nível médio e até mesmo de nível superior, na medida em que nossos estudantes vêm tendo contato cada vez mais jovens com smartphones, tablets e notebooks, com acesso constante à internet. O ensino de Ciências de maneira geral, baseado em aulas expositivas sem nenhuma interação com o cotidiano dos alunos, acaba se tornando pouco motivador, podendo resultar em desinteresse e baixo desempenho no que diz respeito à assimilação dos conceitos estudados. No caso específico da Física, aliar novas tecnologias com demonstrações experimentais dos fenômenos físicos, tradicionais ou não, é uma interessante possibilidade para abordar a Física como ciência capaz de descrever a natureza para alunos nativos digitais (PRENSKY, 2001). 
Não pretendemos desconsiderar a base científica envolvida na compreensão e construção dos produtos tecnológicos, mas sim, buscamos a construção de uma visão tecnológica inserida na solução de problemas concretos onde, através da manipulação de novas tecnologias os estudantes aprendam não somente como usá-las, mas também reflitam sobre as implicações sociais e as diversas possibilidades de utilização dessas.

Os documentos curriculares oficiais brasileiros demonstram preocupações em relação ao currículo e abordagem dos conteúdos em todos os níveis de escolaridade, visto que o espaço escolar apresenta-se cada vez menos atraente aos estudantes. A análise dos Parâmetros Curriculares Nacionais (PCN) (BRASIL, 2000) e das Diretrizes Curriculares Nacionais para o Ensino Médio (DCNEM) (BRASIL, 1998; 2012; 2013), revela a necessidade da escola entrar em consonância com as novas tecnologias que se instauram na sociedade. Observamos que efetivas reformas educacionais ocorrem lentamente, muitas vezes sofrendo resistência por parte dos professores, enquanto que as inovações tecnológicas ocorrem diariamente.

No que se referem ao Ensino Médio, as Bases Legais do PCN (BRASIL, 2000), estabelecem dois fatores que determinam a urgência em repensar novos direcionamentos do ensino nessa etapa escolar, a saber: (1) a "revolução informática"; e (2) a ruptura tecnológica característica da chamada terceira revolução técnico-industrial causada pelos avanços da microeletrônica.

A produção de novas tecnologias e a inserção das mesmas no cotidiano dos alunos, fora e dentro do ambiente escolar, inferem propostas de reforma curricular, em particular para o Ensino Médio (BRASIL, 2000), pautadas no conhecimento e seus desdobramentos, onde a formação do aluno deve desenvolver a capacidade de pesquisar, buscar informações, analisálas e selecioná-las além de capacitá-lo a aprender, criar, formular, ao invés do simples exercício de memorização.

O artigo 12 das DCNEM (BRASIL, 2012), afirma que os conteúdos, as metodologias e as formas de avaliação serão organizados de tal forma que ao final do Ensino Médio o educando demonstre domínio dos princípios científicos e tecnológicos que presidem a produção moderna. Nesse mesmo documento, com relação à proposta curricular, se estabelece a pesquisa como princípio pedagógico, possibilitando ao estudante ser protagonista na investigação e na busca de respostas em um processo autônomo de (re)construção do conhecimento.

A área de Ciências da Natureza, Matemática e suas Tecnologias, objetiva a constituição de habilidades e competências que permitam ao educando entender a relação entre o desenvolvimento das Ciências Naturais e o desenvolvimento tecnológico, e associar as diferentes tecnologias aos problemas que se propuseram e propõem solucionar, além de aplicar as tecnologias associadas às Ciências Naturais na escola, no trabalho e em outros contextos relevantes para sua vida (BRASIL, 1998).

Segundo as Orientações Educacionais Complementares aos PCN (BRASIL, 2002), os professores devem se voltar com especial atenção, à característica fundamental da ciência: a sua dimensão investigativa. O referido documento salienta a importância que os métodos de 
ensino sejam modificados, capacitando o aluno: a responder perguntas e a procurar as informações necessárias, desenvolver atitudes reflexivas e autocrítica diante dos possíveis erros e gerenciar os conhecimentos adquiridos.

Nesse contexto, é necessário repensar as atividades de ensino e, especificamente, no que concerne às atividades experimentais, extrapolar o modelo tradicional que se dá através de roteiros preestabelecidos, equipamentos tradicionais e objetivos determinados em verificar leis científicas (BORGES, 2002). Araújo e Abib (2003) ressaltam que o uso da experimentação como estratégia de ensino de Física tem sido alvo de inúmeras pesquisas nos últimos anos, sendo que a forma e os meios com que a experimentação é empregada apontam para diversas tendências no uso desta estratégia. Concebemos que a utilização de novas tecnologias aliadas às atividades experimentais pode potencializar a eficiência do laboratório de ensino de Física. A experimentação se torna uma forma de interligação entre o mundo dos objetos, o mundo dos conceitos, leis e teorias e o das linguagens simbólicas (SERÉ; COELHO; NUNES, 2003).

Os computadores, por exemplo, vêm sendo amplamente utilizados no meio científico, tendo contribuído para inúmeras descobertas e criação de complexos modelos. No entanto, nos ambientes escolares são frequentemente usados apenas como fonte de consulta e apresentação de textos (HAAG; ARAÚJO; VEIT, 2005). Nesse cenário, empregar computadores com softwares de tratamento de dados ou simulação como, por exemplo, Matlab (MATHWORKS, 2014), Labview (NATIONAL INSTRUMENTS, 2014), Tracker (CABRILLO COLLEGE, 2014), Modellus (DORNELES e VEIT, 2006; DORNELES e VEIT, 2008; MODELLUS, 2014) ou Algodoo (DA SILVA et al., 2014) são alternativas interessantes. Além disso, inseri-los na aquisição automatizada de dados em laboratórios didáticos científica, possibilita ao aluno compreender o estágio atual das Ciências e a aquisição em tempo real de dados (HAAG; ARAUJO; VEIT, 2005).

Utilizar placas de aquisição de dados para construir os próprios experimentos é uma alternativa de baixo custo quando comparamos com equipamentos didáticos praticados, com elevados preços, por grandes empresas. Em diversas situações, observamos ainda durante nossas atividades no campus Vitória do Instituto Federal do Espírito Santo que os equipamentos comprados de empresas especializadas em material didático eram bastante limitados, na medida em que não se podia fazer adaptações buscando novas abordagens. Por outro lado, também notávamos que aulas práticas tradicionais, no sentido de uma montagem pronta, com pouca interação e liberdade de investigação, baseadas em cronômetros, réguas e papel milimetrado desmotivavam os estudantes, principalmente aqueles de níveis básicos do ensino, acostumados a lidar diariamente com equipamentos repletos de tecnologia. Em um experimento de análise de queda livre não é de se espantar que os resultados ainda tenham sido pouco animadores, uma vez que falamos em décimos de segundos para quedas de alturas típicas de um ser humano. E não tendo uma boa medida até os milésimos de segundos, o experimento conduzia a valores de $g$ pouco precisos. 
Utilizar equipamentos que permitissem a obtenção de dados em tempo de coleta mais curto, para então passar o tempo de aula discutindo os conceitos envolvidos se mostrava a melhor alternativa para motivar os estudantes. Permitir que eles participassem do processo de construção, visualizando os problemas e propondo novas soluções em busca de melhores resultados, certamente faria com que compreendessem mais o caráter investigativo das ciências e seu papel de descrição da natureza.

Além disso o trabalho de construção de um aparato experimental desmistifica o processo de aquisição automática de dados, permitindo que o aluno manipule os sensores, faça medidas manuais, trabalhe com sistemas de detecção, e explore softwares para, somente então, operar sistemas automáticos de aquisição de dados (HAAG; ARAÚJO; VEIT, 2005). Permite que professor e alunos observem as limitações existentes na prática, onde não existem condições ideais, e tenham contato com eletrônica e linguagem de programação.

Nessa linha de pensamento a elaboração e construção de experimentos para coleta de dados pode ser implementada de maneira muito interessante e eficaz através da plataforma de hardware livre Arduino, permitindo otimização do tempo para coleta de dados, maior número de medidas e com maior precisão, em sistemas onde seria muito difícil e extremamente tedioso coletar dados manualmente. Assim, a utilização do Arduino no ambiente escolar, pode ser tornar uma ferramenta poderosa na complementação do processo de ensino e na consolidação do processo de aprendizagem. Baseados então em todas as possibilidades que o Arduino fornecia, e visando solucionar as dificuldades de medida no experimento de queda livre, iniciamos o desenvolvimento de equipamento capaz de determinar o tempo de queda de objetos abandonados para que com estes parâmetros pudéssemos determinar o valor da aceleração da gravidade local.

\section{Arduino e suas potencialidades}

O uso da plataforma Arduino tem se tornado cada vez mais comum em várias áreas da ciência. O projeto teve início em 2005, com o objetivo educacional de possibilitar a pessoas não especialistas (seja na área de programação ou em eletrônica) desenvolver aplicações de objetos e ambientes interativos (ARDUINO, 2013). A plataforma surgiu como projeto de pesquisa no Instituto de Ivrea, localizado na Itália, sendo idealizado por pessoas de diversas partes do mundo.

Estima-se que mais de 500 mil placas Arduino e suas variantes tenham sido vendidas até o momento e tal sucesso deve-se à facilidade de sua utilização, ou seja, pessoas que não são da área técnica podem, rapidamente, aprender o básico e criar seus próprios projetos em um intervalo de tempo relativamente curto (MCROBERTS, 2012), além do baixo custo e de todo projeto eletrônico possuir acesso público e gratuito. Existem hoje grandes comunidades de pessoas utilizando a plataforma Arduino, compartilhando códigos-fonte e hardware para que a produção open source se espalhe. 
Desde seu uso para música, iluminação, hobby ou entretenimento em geral, até para ser usada em protótipos de próteses mecânicas ou robôs espaciais, a pequena placa microcontrolada vem conquistando espaço na área de ciência e tecnologia devido à facilidade do uso e aprendizado e às inúmeras possibilidades que o Arduino traz consigo.

O Arduino apresenta diferentes tipos de placas. A mais comum é o Arduino Uno, que possui 14 entradas/saídas digitais, 6 entradas/saídas analógicas e um microcontrolador ATmega328, além de outros componentes eletrônicos importantes para o ideal funcionamento da placa. Existe também o modelo Arduino Nano, que é muito menor que o modelo Uno e apresenta as mesmas configurações, ideal para projetos onde se tem pouco espaço ou não é possível a inserção de muito peso. A placa Arduino mais sofisticada é a Arduino Mega. Esta placa apresenta um microcontrolador ATmega2560, 54 entradas/saídas digitais, 16 entradas/saídas analógicas e outros recursos importantes de hardware.

Sensores como medidores de temperatura, pressão, umidade, distância, gases, fototransistores podem ser utilizados como entrada e leds, motores, displays, alto-falantes (que podem estar ou não correlacionados aos sinais dos sensores de entrada) podem ser utilizados como saída. Essa versatilidade estimula a utilização do Arduino em experiências didáticas, permitindo o controle de vários dispositivos. O microcontrolador na placa é programado usando a linguagem Processing, que se assemelha à linguagem $\mathrm{C}$, e foi desenvolvida no Massachusetts Institute of Technology (MIT) buscando dar acessibilidade a pessoas sem experiência em programação. Além disso, o software de programação é multiplataforma, podendo ser usado no Windows, Linux ou Mac.

O Arduino pode ser comandado também pelo Scratch para ler sensores. Scratch é uma linguagem de programação visual que foi desenvolvida em 2007 pelo Lifelong Kidendarten Group, grupo de pesquisa liderado por Mitchel Resnick, e que faz parte do Media Labs do MIT. O objetivo era criar um ambiente de programação ligado a objetos com características essenciais para incentivar, de modo intuitivo, o uso por crianças e adolescentes. Um grupo independente fez a adaptação deste software, chamando de Scratch 4 Arduino, unificando o uso do Scratchcom a plataforma Arduino, objetivando facilitar o acesso às funcionalidades do Arduino, utilizando um ambiente com melhor usabilidade (BASTOS; BORGES; D'ABREU, 2010).

No que tange o uso das potencialidades do Arduino para o ensino de física no Brasil, os sistemas de aquisição de dados montados com essa plataforma podem ser grandes aliados pois há a possibilidade de se desenvolver equipamentos de laboratório capazes de medir grandezas, tornando possível a experimentação da teoria ensinada em sala e permitindo que esta seja visualizada na prática. Além disso o estudante terá participado do processo de construção, e poderá indicar novas abordagens ou aplicações ao aparato, evitando as chamadas "caixas pretas" dos kits prontos, uma vez que estes possuem limitações quanto ao uso em experimentos diferentes daqueles para os quais eles foram projetados, o que limita a sua utilidade didática. De fato, são pontos negativos abordados por alguns autores com relação a esses kits, a presença 
de circuitos eletrônicos e programas produzidos por empresas especializadas, vendidos a preços relativamente altos e que não permitem modificações livres por parte dos educadores e estudantes (CAVALCANTE, TAVOLARO e MOLISANI, 2011; LAUDARES et al., 2014; SOUZA et al., 2011; BEZERRA et al., 2009).

Nesse sentido diversos trabalhos utilizando Arduino vêm sendo desenvolvidos ao longo dos anos evidenciando sua versatilidade. Experimentos abordando carga e descarga de capacitores (CAVALCANTE; TAVOLARO; MOLISANI, 2011), mapeamento de campos magnéticos de ímã de neodímio e calibragem de sensor de temperatura (LAUDARES et al., 2014), estudos de oscilações amortecidas e transferência radiativa de calor (SOUZA et al., 2011), abordagens envolvendo ondas estacionárias (BEZERRA JR et al., 2009) e outros trabalhando em fenômenos acústicos usando o tubo de Kundt (CAVALCANTE, 2013). Observação do fenômeno das marés atmosféricas utilizando a placa Arduino para aquisição de dados, permitindo a discussão de conceitos ligados à gravitação, fluidos e física térmica (CARVALHO; AMORIM, 2014) e estudo de sistemas acelerados (ROCHA; MARRANGHELLO; LUCCHESE, 2014) são outros exemplos que podem ser citados.

Em uma breve revisão da produção científico-tecnológica envolvendo o Arduino, percebemos que a maioria dos trabalhos estão sendo desenvolvidos em universidades, com foco nos cursos de graduação ou em projetos relacionados à robótica educacional. Argumentamos que o uso do Arduino deve ser aplicado a todos os níveis de ensino, uma vez que tem a capacidade de despertar o interesse do aluno durante a construção do aparato. Em especial a utilização do Arduino dentro do ensino da Física para o Ensino Médio, ressoa com os documentos oficiais (BRASIL, 2000; 2002; 2013), e está em consonância com os estudantes nativos digitais. Experimentos nos quais o aluno pode interagir, construir circuitos e programar potencialmente despertam interesse, tornando-se um elemento motivador para as aulas de Física.

Se além disso os estudantes forem chamados a pensar, manusear, construir, executar, ver o que dá certo, depurar o que está errado e reexecutar, mergulhando em seus conhecimentos físicos para entender os resultados experimentais obtidos, certamente chegarão nos níveis de ensino seguintes com capacidade de raciocínio e de resolução de problemas mais apuradas, seja qual for a área do conhecimento. Por ter uma linguagem de programação simples, o uso do Arduino pode ser encorajado inclusive ao professor que não sabe programar, aprendendo e desenvolvendo o trabalho junto com seus alunos, buscando abordagens do cotidiano, de coisas que façam sentido para o aluno, sendo um mediador do conhecimento e não estando mais no papel de "dono do conhecimento", em uma abordagem tipicamente construcionista (BASTOS; BORGES; D’ABREU, 2010). Se trouxermos a ciência para uma realidade mais próxima do aluno, utilizando situações reais, certamente teremos ótimos resultados (LIMA, 2012).

\section{Método e materiais}

A ideia base da construção do aparato foi distribuir, ao longo de uma haste metálica vertical, cinco anéis metálicos de espaçamentos preestabelecidos entre si, contendo sensores 
infravermelhos digitais capazes de captar a passagem de objetos. O primeiro sensor, posicionado no extremo superior da haste, ao enviar um sinal ao Arduino, inicia a contagem do tempo caso um objeto abandonado passe por ele. Quando o objeto em queda passar pelos sensores inferiores, estes enviarão seus respectivos sinais ao Arduino, fazendo com que o microcontrolador adquira os tempos de passagem, calculando e exibindo o tempo decorrido entre cada intervalo em uma tela LCD.

Com o tempo fornecido pela placa e a distância entre os anéis, podem ser realizados cálculos simples para obter o valor da aceleração da gravidade.

Se uma esfera for abandonada do repouso, a partir de uma altura H' acima de um nível de referência inicial, tomado como origem, a equação que descreve sua altura $y$ em função do tempo $t$ será (HALLIDAY; RESNICK; KRANE, 2002; HALLIDAY; RESNICK; WALKER, 2012)

$$
y=\mathrm{H}^{\prime}-\frac{g}{2} t^{2}
$$

onde foi escolhido o eixo vertical orientado para cima e $g$ é o módulo da aceleração da gravidade. Mas, analisando agora esse movimento a partir do nível de referência tomado como origem, considerando aí também o início da contagem de tempo, pode-se observar que a esfera passa por ele com velocidade diferente de zero, resultado do movimento acelerado percorrendo a distância H'. Após um intervalo de tempo $\Delta t$ a esfera terá percorrido uma distância $\mathrm{H}$ de maneira que

$$
-\mathrm{H}=-v_{0} \Delta t-\frac{g}{2} \Delta t^{2}
$$

ou então

$$
\mathrm{H} / \Delta \mathrm{t}=v_{0}+\frac{g}{2} \Delta t
$$

Assim, se analisarmos o movimento do corpo repetidas vezes, sempre a partir de um mesmo nível inicial como origem dos tempos, podemos determinar sua aceleração medindo os intervalos de tempo que ele leva para percorrer distâncias com diferentes valores de H. Montando um gráfico de $\mathrm{H} / \Delta t$ em função de $\Delta t$, o valor do coeficiente angular da reta será exatamente a metade de $\mathrm{g}$.

Uma vantagem nessa abordagem é a independência do resultado final com relação ao valor H' acima do nível de referência onde a esfera é abandonada. Quanto maior esse valor, maior a velocidade $v_{0}$, ou seja, maior o coeficiente linear da reta de $\mathrm{H} / \Delta t$ em função de $\Delta t$. No entanto o coeficiente angular, que é o nosso objeto de interesse, permanece inalterado. Por isso, se um grupo de alunos estiver realizando o experimento, não é necessário que se preocupem com a posição vertical exata do abandono.

O modelo do equipamento que foi idealizado e construído é mostrado em detalhes na Fig. 1. São destacadas a haste de queda livre (a), que é a estrutura onde estão os anéis metálicos (b) pelos quais o corpo abandonado deverá passar, e os sensores (d) ao longo de seu percurso 
que forneceram o sinal para o Arduino determinar o tempo de queda, além das caixas de circuitos dos sensores (c) e da central de processamento (e), onde o sinal dos sensores será tratado pelos circuitos e pelo Arduino, exibindo numa tela LCD o tempo de queda dos objetos.

Cada uma das partes constituintes será tratada em detalhes nos próximos tópicos demonstrando seu funcionamento e fornecendo os detalhes técnicos essenciais que facilitam a compreensão da construção.

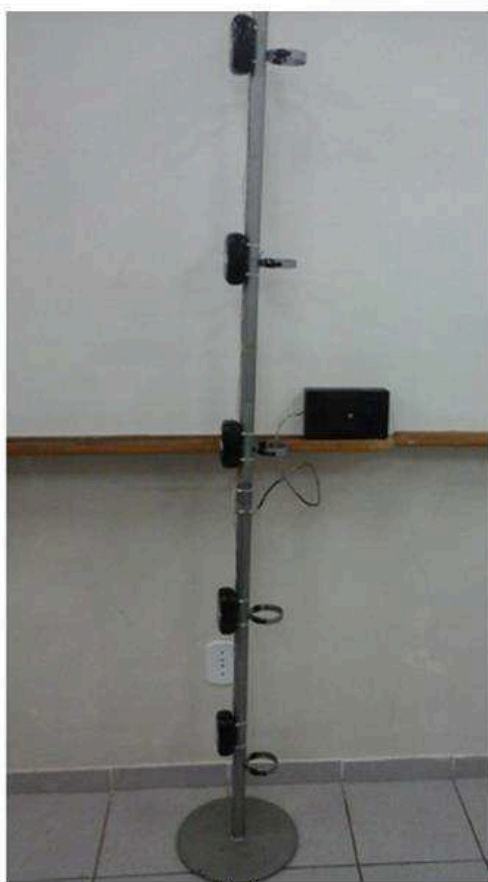

(a)

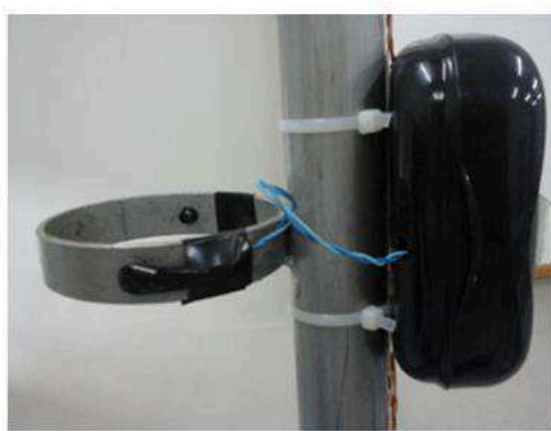

(b)

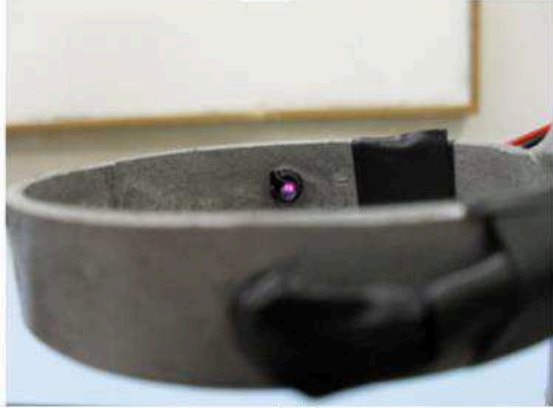

(d)

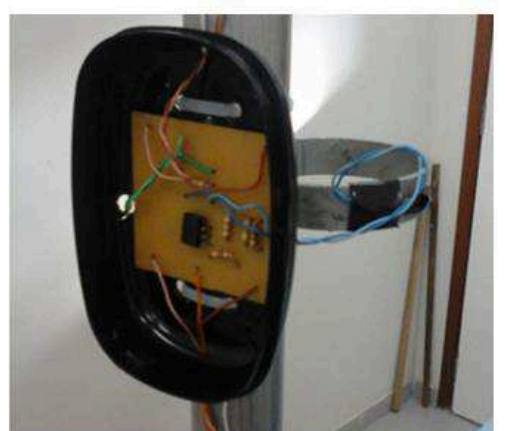

(c)

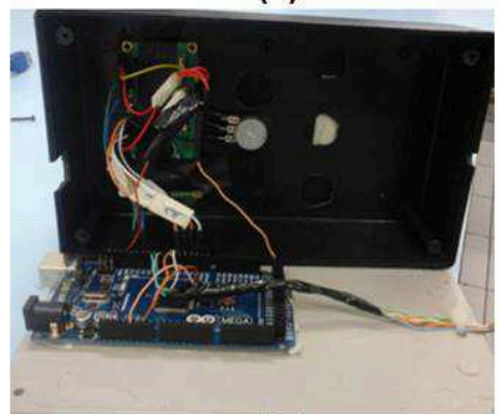

(e)

Fig. 1 -Detalhes da estrutura do dispositivo de queda livre. Em (a) vemos a haste de queda livre e a caixa com central de processamento, em (b) os anéis metálicos onde estão fixados os sensores infravermelhos, em (c) uma das caixas com circuito onde o sinal é tratado, em $(d)$ o detalhe dos sensores infravermelhos e em (e) o interior da central de processamento com destaque para a placa Arduino.

\section{Haste de queda livre}

A haste de queda livre é composta por uma estrutura cilíndrica metálica que fica presa perpendicularmente à uma base circular (Fig. 1.a). Nesta estrutura estão dispostos, em espaçamentos preestabelecidos, cinco anéis metálicos onde são fixados sensores infravermelho digitais (Fig. 1.b).

O sensor mais ao alto é o disparador do cronômetro: quando um objeto passa por ele, este envia um sinal ao Arduino para que se comece a contagem do tempo. O sensor mais baixo, por sua vez, termina a contagem e faz com que o Arduino inicie os cálculos dos tempos armazenados e exiba os intervalos no display LCD. 
Os sensores são dispostos nos anéis de forma que o emissor fique alinhado com o receptor (Fig. 1.d) fazendo com que este sempre receba o sinal enviado pelo emissor. Caso um objeto atravesse o anel, a emissão será temporariamente interrompida, o receptor detectará essa ausência e enviará um sinal para a placa Arduino, indicando que o corpo acabou de passar por aquela posição. Contudo, o sinal elétrico captado por esses sensores infravermelho não pode ser diretamente enviado ao Arduino devido à sua baixa intensidade e à ruídos eletromagnéticos que podem prejudicar sua interpretação (NILSSON; RIEDEL, 2008). O sinal é tratado nas pequenas caixas (Fig. 1.c) localizadas atrás da haste, através de um circuito comparador baseado em um amplificador operacional TL081. Cada sensor, par de emissor e receptor, possui um circuito para envio do sinal à placa na central de processamento. O esquema desse circuito é apresentado na Fig. 2.

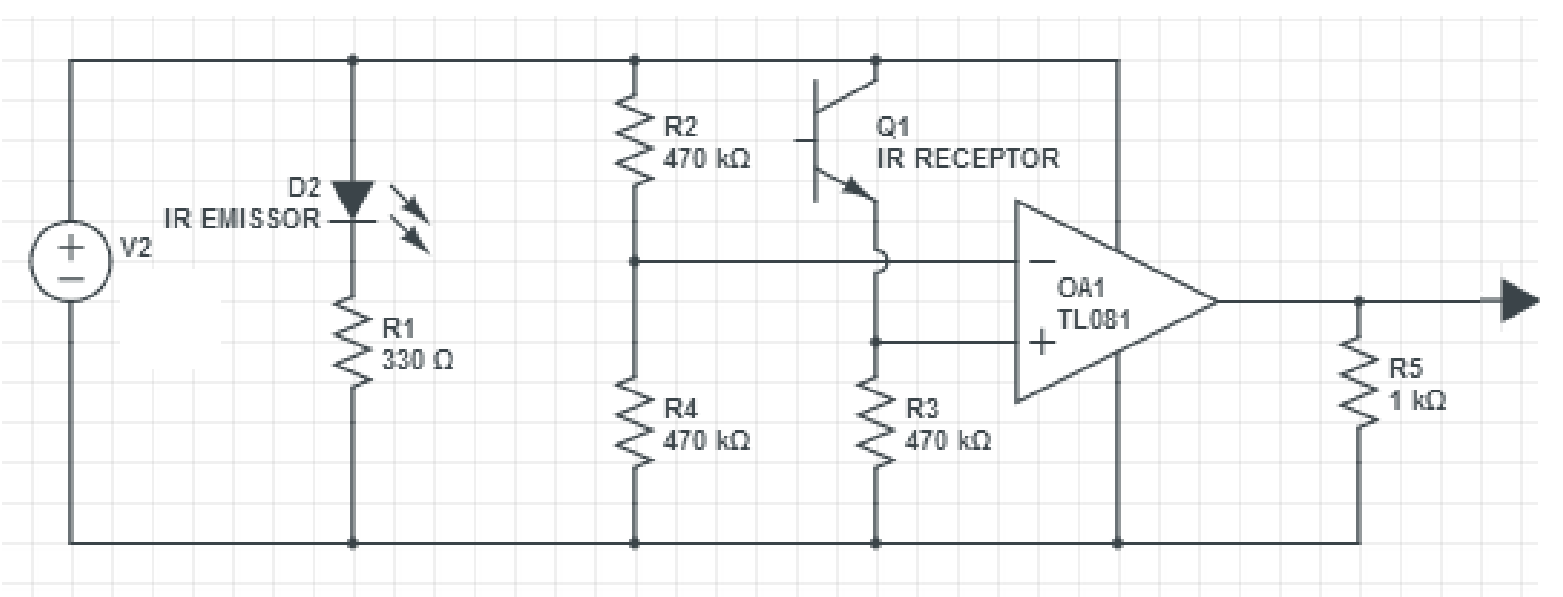

Fig. 2 - Circuito eletrônico para os sensores

No circuito, os componentes D2 e Q1 representam o par de emissor e receptor, respectivamente, que ficam fixados nos anéis da haste de queda. Quando o sinal infravermelho está chegando ao receptor, eles permitem a condução de corrente, que faz com que a tensão do ponto ligado à entrada não inversora (com o sinal +) do amplificador operacional (OA1) seja alta (5 volts). O amplificador operacional age como um comparador; se a tensão da entrada não inversora (+) for maior que o da entrada inversora (-), então o amplificador devolverá um sinal igual à tensão da fonte na saída (neste caso $5 \mathrm{~V}$ ), o oposto ocorre se a tensão na entrada inversora for maior que na entrada não inversora, então o sinal na saída será, neste caso, 0V (PERTENCE JUNIOR, 2011). Caso um objeto interrompa o sinal infravermelho entre o emissor e o receptor, a tensão na entrada não inversora será momentaneamente igual à $0 \mathrm{~V}$, fazendo com que o Arduino perceba o nível lógico 0 em uma de suas entradas digitais que recebem o sinal dos sensores. 


\section{Central de processamento}

A central de processamento é onde ficam instalados o Arduino, o potenciômetro para regular o contraste da tela LCD e a própria tela de um display LCD. Na Fig. 1.e é possível visualizar a conexão dos componentes mencionados, que são alimentados através de cabo USB conectado em um computador ou em uma fonte simples de aparelhos eletrônicas (até 12V). A placa Arduino Mega, também observada na mesma figura, é a responsável por processar toda a informação enviada pelos sensores, realizar cálculos e imprimir os resultados no display LCD.

Esse display é um dispositivo capaz de exibir informações enviadas pelo Arduino, que neste caso envia o tempo decorrido de um objeto, desde que é abandonado até passar por um determinado sensor. A tela é capaz de exibir 32 caracteres (entre números, símbolos e letras), distribuídos em duas linhas de dezesseis colunas. Na Fig. 3, apresentamos algumas mensagens exibas ao usuário. Ao se ligar o programa, primeiramente é exibido o título do projeto, em seguida uma mensagem indicando que tudo está pronto para que o objeto seja abandonado na haste de queda livre. Se o objeto é abandonado e passa pelos sensores do primeiro anel metálico, exibe-se uma mensagem de reconhecimento de que o objeto está em queda e, quando o objeto passa pelos sensores dos anéis seguintes os intervalos são captados.

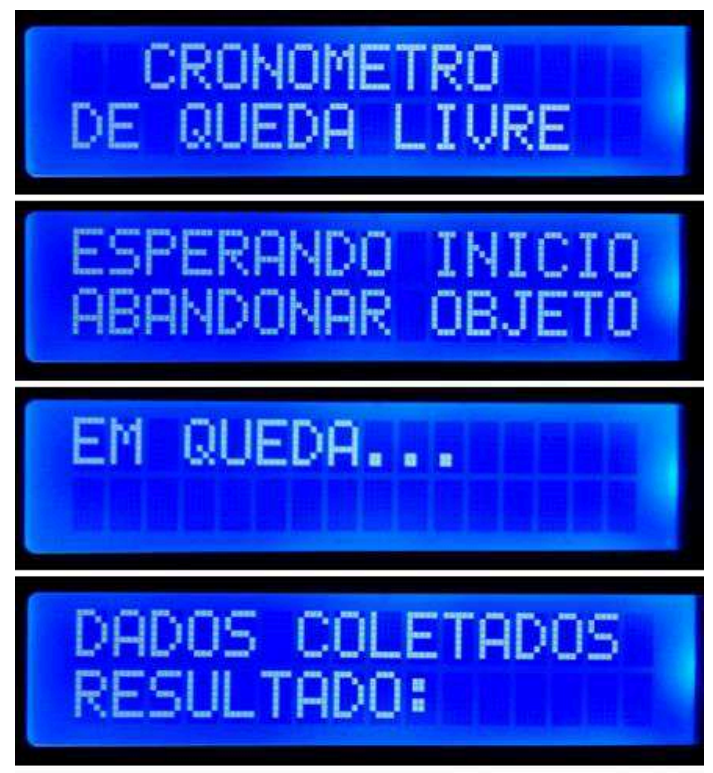

Fig.3 - Mensagens exibidas no display LCD.

Somente quando o objeto passa pelo último sensor a mensagem "em queda" deixa de ser exibida e os cálculos dos intervalos de tempo são realizados, sendo finalmente exibidos os tempos de queda decorridos (Fig. 4). Se eventualmente o experimento não for realizado com a haste corretamente posicionada na vertical, o objeto poderá não passar pelo alinhamento do último par de sensores e essa mensagem seguirá em exibição. A partir do momento em que os 
tempos começam a ser exibidos, eles seguirão aparecendo ciclicamente na tela, na ordem em que foram medidos, enquanto não reiniciamos o sistema.
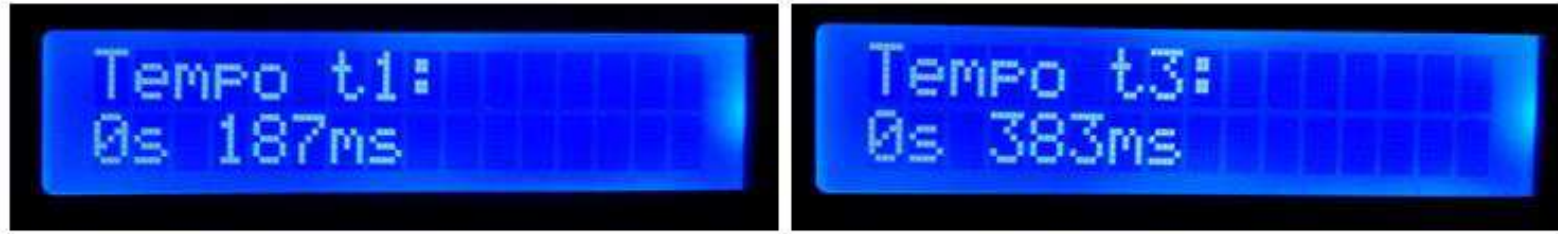

TEMPO t2:

$9 \mathrm{~g} 9 \mathrm{gr} \equiv$

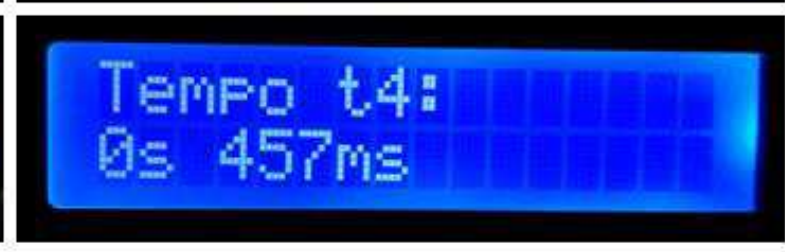

Fig. 4-Exibição no display LCD do tempo de queda ao atravessar cada anel da torre de queda livre.

O Arduino é programado em uma linguagem baseada em $\mathrm{C}$ especialmente desenvolvida para esta placa. Devido ao seu vasto uso atualmente, existem muitas bibliotecas de algoritmos prontas para uso, muitas delas distribuídas pelos próprios desenvolvedores da placa, como é o caso da biblioteca LyquidCrystal.h, usada para facilitar a interface do Arduino com a tela LCD (ARDUINO, 2014).

O programa sendo executado neste projeto é composto, basicamente, de duas partes. A primeira é um cronômetro baseado na função millis(), que atribui à alguma variável previamente especificada o tempo, em milissegundos, do momento em que é requisitada. No nosso caso esse tempo será tomado entre os pares de sensores em diferentes anéis metálicos.

Uma vez calculado o resultado, este é exibido pelo Arduino no display LCD, que é a segunda parte do programa. Em anexo, disponibilizamos o código que contém anotações sobre cada uma de suas partes, facilitando seu entendimento e permitindo assim que professores e alunos interessados no projeto possam reproduzir o experimento sem a necessidade de iniciar os trabalhos do zero.

\section{Resultados e Discussão}

Após a montagem do equipamento, foi realizada a medição dos quatro trechos tomados como referência para a medição dos tempos (Fig. 5).

Buscamos nivelar a base para manter a haste de queda livre na vertical, evitando que a trajetória do corpo em queda ocorresse em uma diagonal. Mesmo assim, trajetórias diferentes de uma vertical perfeita foram observadas, já que no momento do abandono manual do corpo em queda o usuário poderia fornecer a ele quantidade de movimento no plano horizontal. Contudo, esses tempos medidos foram considerados, já que a diferença percentual no percurso 


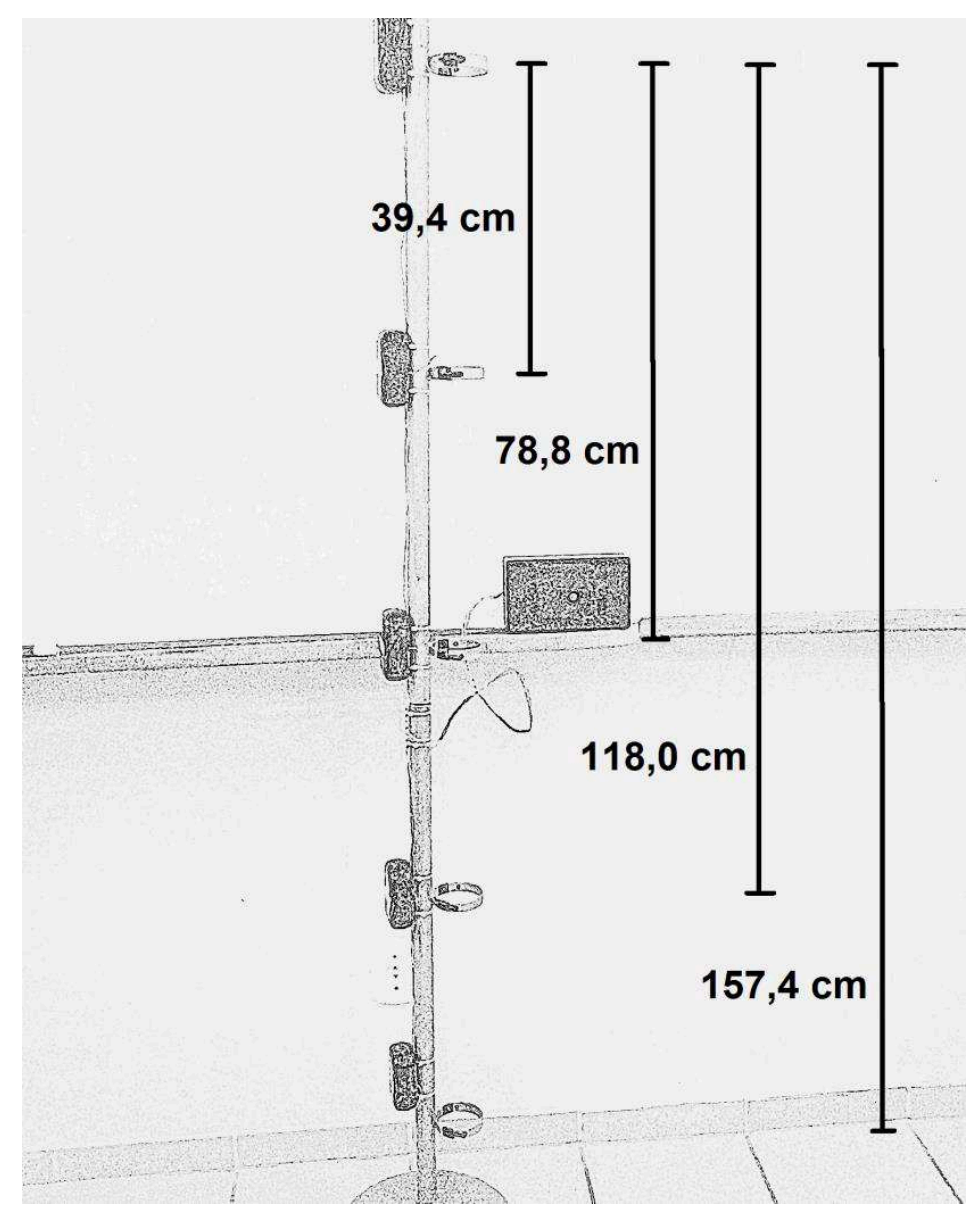

Fig. 5 - Ilustração dos comprimentos para os quatro trechos utilizados para medição dos intervalos de tempo.

seria sempre muito baixa. O diâmetro dos anéis onde estavam localizados os sensores era de $7,4 \mathrm{~cm}$ e de modo que, se um objeto pontual partisse do centro do primeiro anel e passasse próximo à borda do último anel, ele percorreria uma distância apenas $0,025 \%$ maior dos que os $154,7 \mathrm{~cm}$ do percurso perfeitamente vertical, uma diferença que não chega a $0,1 \mathrm{~cm}$, que é a medida mais precisa da régua utilizada. Considerando que o objeto abandonado é uma esfera com 3,0 cm de diâmetro, essa diferença percentual seria então ainda menor já que seu centro estaria sempre ao menos a 1,5 cm da borda do anel. Assim, o erro devido a esse desvio da vertical foi desconsiderado.

Foram coletados os tempos de queda para 51 eventos, sendo que em 32 casos a esfera interrompeu o sinal dos quatro sensores, em 14 casos apenas dos sensores 1,2 e 3 , e nos últimos 5 casos apenas dos sensores 1, 2 e 4. Optamos por manter todos os dados, mesmo nos casos em que não obtivemos as quatro medidas, justamente por ser essa a situação mais real do dia a dia em uma aula no laboratório de Física, onde os estudantes nem sempre terão todo o cuidado possível no manuseio. Para aos dados de cada queda, tendo os tempos e conhecendo as distâncias percorridas, obtemos o coeficiente angular da reta média através do gráfico de $\Delta L / \Delta t$ por $\Delta t$. A Tabela 1 apresenta os valores de $\Delta L, \Delta t$ e $\Delta L / \Delta t$ obtidos em um evento de queda 
livre típico com o nosso aparato, e a Fig. 6 mostra uma análise para um conjunto de tempos medidos nessa amostra.

Tabela 1: Dados medidos para um evento de queda livre onde foram medidos os comprimentos $\Delta L$ para cada trecho e os respectivos intervalos de tempo $\Delta t$. Na terceira coluna é apresentada o cálculo de $\Delta L / \Delta t$.

\begin{tabular}{l|ccc}
\hline & $\boldsymbol{\Delta L}(\boldsymbol{m})$ & $\boldsymbol{\Delta t}(\boldsymbol{s})$ & $\Delta \boldsymbol{L} / \Delta \boldsymbol{t}$ \\
\hline $\boldsymbol{I}$ & 0,394 & 0,175 & 2,251429 \\
$\boldsymbol{2}$ & 0,788 & 0,282 & 2,794326 \\
$\mathbf{3}$ & 1,180 & 0,368 & 3,206522 \\
$\mathbf{4}$ & 1,574 & 0,442 & 3,561086 \\
\hline
\end{tabular}

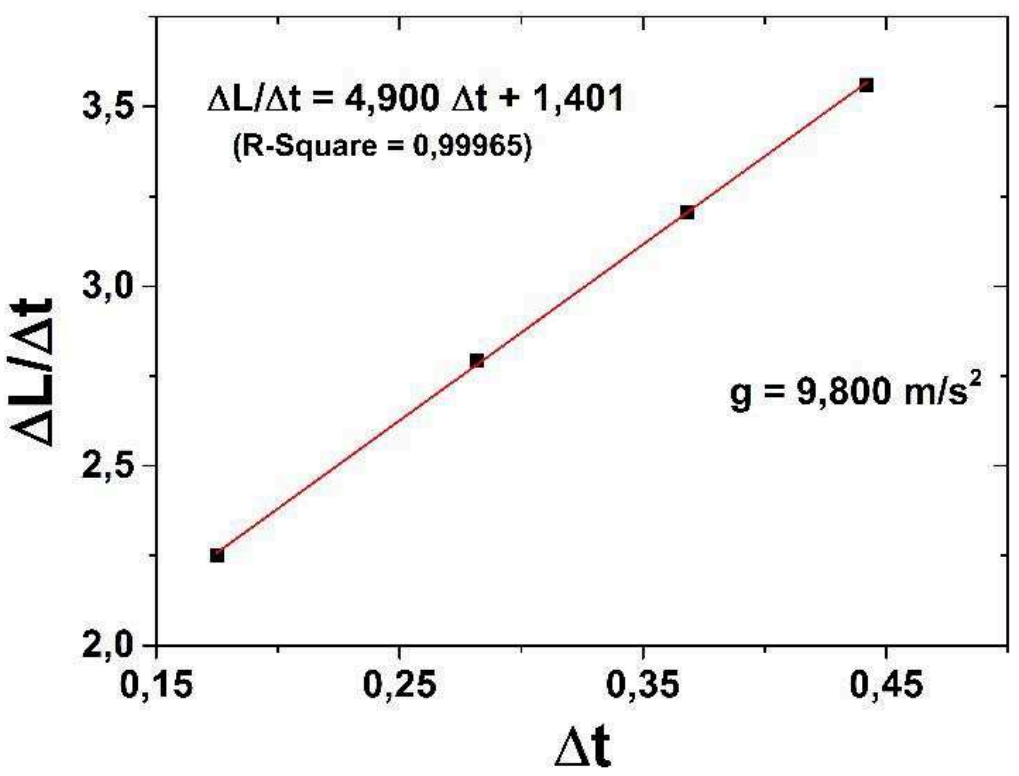

Fig. 6 - Gráfico de $\Delta L / \Delta t$ versus $\Delta t$ com ajuste linear evidenciado pela linha vermelha. O módulo da aceleração da gravidade, $g=9,800 \mathrm{~m} / \mathrm{s}^{2}$, é o dobro do coeficiente angular da reta média.

Verificamos que a equação (3) descreve os dados da Fig. 6, como pode ser visto pelo ajuste linear (curva vermelha). Uma vez conhecendo o coeficiente angular, o módulo da aceleração da gravidade local é obtido ao multiplicá-lo por 2. Para essa amostra o módulo da aceleração da gravidade local foi estimado em $9,800 \mathrm{~m} / \mathrm{s}^{2}$, que sozinho já é muito próximo dos valores de aceleração da gravidade apresentados nos livros. Por conta da pequena altura de queda e da massa elevada da esfera, a resistência do ar não produz um desvio elevado na medida 
da aceleração da gravidade, além de não ter sido o objetivo desse trabalho analisar a dependência dessa variável. O estudo do efeito da resistência do ar no processo de queda livre utilizando esse dispositivo e alterando massa, forma, material e textura da superfície do objeto em queda será tema de futuros trabalhos.

O procedimento feito na Fig. 6 foi realizado em mais 50 amostras e o valor da aceleração da gravidade local média, com desvio padrão, foi de 9,801 $\pm 0,100 \mathrm{~m} / \mathrm{s}^{2}$. O valor com o desvio padrão indica que o instrumento desenvolvido apresenta uma boa margem de confiança em suas medidas, já que a aceleração da gravidade local na cidade de Vitória é de $9,786 \mathrm{~m} / \mathrm{s}^{2}$ (BERQUÓ, 2009), com nosso resultado possuindo um erro de apenas $1 \%$. Além disso o cálculo médio de $R^{2}$ considerando o ajuste linear das 51 medidas nos leva ao valor 1 mesmo que consideremos até a terceira casa decimal, o que mais uma vez mostra a confiança dos resultados apresentados.

\section{Considerações finais}

Neste artigo, construímos um aparato experimental no qual utilizamos a plataforma de hardware livre Arduino para medir o módulo da aceleração da gravidade local para o movimento de queda livre de uma esfera. Apresentamos um breve resumo da construção e funcionamento do equipamento, assim como o circuito e o algoritmo utilizado para automatizar as medidas. Essas informações foram apresentadas em um nível de detalhes tal que a tarefa de reproduzir o experimento proposto fosse facilitada para professores e alunos interessados, sem que fosse necessário iniciar o projeto do zero. Propusemos então uma abordagem alternativa de estudo da física utilizando o Arduino em atividades experimentais, abrindo canais de discussão entre alunos e professores ao propor a elaboração de um instrumento para medir uma grandeza física utilizando conhecimentos básicos de programação e eletrônica. Desta forma, as diversas etapas envolvidas no projeto como construção, solução das dificuldades no desenvolvimento, propostas de melhorias e indicação de novas abordagens permitem o enriquecimento do processo de aprendizagem do aluno.

Além disso, tendo em vista o custo de equipamentos didáticos comercializados por empresas especializadas em kits experimentais, a possibilidade de montar os próprios experimentos, juntamente com os alunos, é uma ótima alternativa para as unidades de ensino. Para a confecção do equipamento relatado nesse trabalho, considerando a estrutura metálica, a placa Arduino, os componentes eletrônicos e estéticos, foram investidos em torno de $\mathrm{R} \$ 300,00$. Esse valor, mesmo podendo estar ainda fora da realidade de investimento em unidades de ensino de regiões mais carentes de recursos, é certamente muito menor do que o investimento necessário para a compra de equipamentos similares de empresas do ramo, tendo então uma boa relação custo $\mathrm{x}$ benefício quando tratamos de equipamentos didáticos de laboratório.

O equipamento foi capaz de medir o módulo da aceleração da gravidade na cidade de Vitória, ES ao nível do mar e obter um valor de 9,801 \pm 0,100 $\mathrm{m} / \mathrm{s}^{2}$ utilizando 51 eventos de queda de um objeto. Em virtude da baixa altitude de queda e da massa da esfera o atrito do ar 
nesse experimento apresenta uma influência pouco significativa sobre o sistema, e nosso instrumento apresenta então uma boa margem de confiança em sua medida apresentando um erro de apenas $1 \%$ em relação ao valor da aceleração da gravidade local usados na literatura.

\section{Referências}

ARAÚJO, M. S. T. de; ABIB, M. L. V. dos S. Atividades Experimentais no Ensino de Física: Diferentes Enfoques, Diferentes Finalidades. Revista Brasileira de Ensino de Física, v. 25, n. 2, p. 176-194, jun. 2003.

ARDUINO. What is Arduino? Disponível em: <https://www.arduino.cc/en/Guide/Introduction>. Acesso em: 12 ago. 2013.

ARDUINO. LiquidCrystal Library. Disponível em:<http://arduino.cc/en/Reference/LiquidCrystal?from=Tutorial.LCDLibrary\#.UyXmms4Vj_C>. Acesso em: 22 mar. 2014.

BASTOS, B. L.; BORGES, M.; D’ABREU, J. Scratch, arduino e o construcionismo: ferramentas para a educação. In: STED, SEMINÁRIO DE TECNOLOGIA EDUCACIONAL DE ARAUCÁRIA: "DESAFIOS E POSSIBILIDADES DA TECNOLOGIA EDUCACIONAL", I, 2010, Paraná. Anais... ISBN 978-85-98429-02-1. Disponível em:

<http://www.ft.unicamp.br/liag/robotica/downloads/a12.pdf>. Acesso em: 15 mai. 2014.

BERQUÓ, F. R. Investigação do uso da norma $L_{1}$ no ajustamento de redes gravimétricas relativas. 2009. 90f. Dissertação (Mestrado em Geofísica) - Observatório Nacional, Rio de Janeiro.

BEZERRA JR, A. G.; MERKLE, L. E.; SOUZA, E. S. de; SPOLAORE, L. S.; RICETTI, R.; GIMÉNEZ-LUGO, G. A.; SAAVEDRA Filho, N. C. Tecnologias Livres e Ensino de Física: uma experiência na UTFPR. In: SIMPÓSIO NACIONAL DE ENSINO DE FÍSICA, XVIII, 2009, Vitória. Anais. Disponível em:

$<$ http://www.sbf1.sbfisica.org.br/eventos/snef/xviii/sys/resumos/T0302-1.pdf>. Acesso em: 15 mai. 2014.

BORGES, T. A. Novos Rumos para o Laboratório Escolar de Ciências. Caderno Brasileiro de Ensino de Física, Florianópolis, v. 19, n. 3, p. 291-313, dez. 2002.

BRASIL, Conselho Nacional de Educação (CNE). Resolução n. 3, de 26 de junho de 1998: Institui as Diretrizes Curriculares Nacionais para o Ensino Médio. Diário Oficial da República Federativa do Brasil, Brasília, 1998.

BRASIL, MEC. Secretaria de Educação Média e Tecnológica. Parâmetros Curriculares Nacionais: Ensino Médio. Parte III. Ciências da Natureza, Matemática e suas Tecnologias. Brasília: MEC/SEMTEC, 2000. 
BRASIL, Ministério da Educação e Cultura. Secretaria de Educação Básica. Orientações Educacionais Complementares aos Parâmetros Curriculares Nacionais do Ensino Médio, Brasília, 2002.

BRASIL, Ministério da Educação - Conselho Nacional de Educação - Câmara de Educação Básica. Resolução no 2, de 30 de janeiro 2012: Define Diretrizes Curriculares Nacionais para o Ensino Médio. 2012.

BRASIL. Ministério da Educação. Secretaria de Educação Básica. Diretrizes Curriculares Nacionais Gerais da Educação Básica. Brasília: MEC, SEB, DICEI, 2013. 562 p.

CABRillo COllegE. Tracker - Video Analysis and Modeling Tool. Disponível em: $<$ https://www.cabrillo.edu/ dbrown/tracker/>. Acesso em: 22 mar. 2014.

CARVALHO, L. R. M. de; AMORIM, H. S. de. Observando as marés atmosféricas: uma aplicação da placa Arduino com sensores de pressão barométrica e temperatura. Revista Brasileira de Ensino de Física, v. 36, n. 3, p. 3501, 2014.

CAVAlCANTE, M. A.; TAVOLARO, C. R. C.; MOLISANI, E. Física com Arduino para iniciantes. Revista Brasileira de Ensino de Física, v. 33, n. 4, p. 4503, 2011.

CAVAlCANTE, M. A. Novas tecnologias no estudo de ondas sonoras. Caderno Brasileiro de Ensino de Física, Florianópolis, v. 30, n. 3, p. 579-613, dez. 2013.

DA SILVA, S. L.; DA SILVA, R. L.; GUAITOLINI JUNIOR, J. T.; GONCALVES, E.; VIANA, E. R.; WYATT, J. B. L. Animation with Algodoo: a simple tool for teaching and learning physics. Revista Científica do Departamento de Química Exatas, v. 5, n. 2, p. 28-39, nov. 2014.

DORNELES, I. A.; VEIT, E. A. Simulação e modelagem computacionais no auxílio à aprendizagem significativa de conceitos básicos de eletricidade: Parte I - circuitos elétricos simples. Revista Brasileira de Ensino de Física, v. 28, n. 4, p. 487-496, 2006.

DORNELES, I. A.; VEIT, E. A. Simulação e modelagem computacionais no auxílio à aprendizagem significativa de conceitos básicos de eletricidade: Parte II - circuitos RLC. Revista Brasileira de Ensino de Física, v. 30, n. 3, p. 3308, 2008.

GELAMO, E. L. O uso de novas tecnologias aplicadas no ensino de física: uma contribuição para a formação de professores. In: III SIMPÓSIO NACIONAL DE ENSINO DE CIÊNCIA E TECNOLOGIAS, 2012, Ponta Grossa. Anais... Disponível em:

<http://www.sinect.com.br/2012/down.php?id=2733\&q=1>. Acesso em: mar. 2014.

HAAG, R.; ARAÚJO, I. S.; VEIT, E. A. Por que e como introduzir aquisição automática de dados no laboratório didático de Física? Física na Escola, São Paulo, v. 6, n. 1, p. 69-74, mai. 2005 . 
HALLIDAY, D.; RESNICK, R.; KRANE, K. S. Física 1. 5. ed. Rio de Janeiro: LTC, 2002. $368 \mathrm{p}$.

HALLIDAY, D.; RESNICK, R.; WALKER, J. Fundamentos de Física. 9 ed. Rio de Janeiro: LTC, 2012. 356 p. v. 1.

LAUDARES, F. A. L.; CRUZ, F. A. de O.; CRUZ, T. G.; BIGANSOLLI, A. R. Instrumentação para Ensino de Física da UFRuralRJ: experiências docentes para a introdução tecnológica. Revista de Formación e Innovación Educativa Universitaria, v. 7, n. 1, p. 51-58, 2014.

LIMA, M. F. C.; RAPPOPORT, T. A sala de aula, o ensino de física e as novas tecnologias: a professora Magali F. C. Lima entrevista a professora Tatiana Rappoport. Ciência em Tela, Rio de Janeiro, v. 2, n. 1, p. 1-8, 2009.

LIMA, E. C. Conforto térmico em residências como uma proposta de contextualização para o ensino de Termodinâmica no Ensino Médio. 2012. 126 f. Dissertação (Mestrado em Ensino de Física) - Universidade Federal do Rio de Janeiro, UFRJ, Rio de Janeiro.

MATHWORKS. Matlab - The language of technical computing. Disponível em: $<$ http://www.mathworks.com/products/matlab/>. Acesso em: 22 mar. 2014.

MCROBERTS, MICHAEL. Arduino Básico. 1. ed. São Paulo: Novatec, 2012. 456 p.

MODELLUS. Interactive Modelling with Mathematics. Disponível em:

<http://modellus.fct.unl.pt/>. Acesso em: 22 mar. 2014.

NATIONAL INSTRUMENTS. Ambiente gráfico de desenvolvimento de sistemas LabVIEW. Disponível em: <http://www.ni.com/labview/pt/>. Acesso em: mar. 2014.

NILSSON, J. W.; RIEDEL, S. A. Circuitos Elétricos. 8. ed. São Paulo: Pearson, 2008. 592 p. PERTENCE JÚNIOR, A. Amplificadores Operacionais e Filtros Ativos. 7. ed. Rio Grande do Sul: Tekne-Artmed, 2011. 324 p.

PRENSKY, M. Digital natives, digital immigrants. On the Horizon, NBC University, v. 9, n. 5, p. 1-6, oct. 2001. Disponível em: <http://marcprensky.com/writing/Prensky\%20-\%20Digital\%20Natives,\%20Digital\%20Immigrants\%20-\%20Part1.pdf>. Acesso em: 20 mar. 2016.

ROCHA, F. S. da; MARRANGHELLO, G. F.; LUCCHESE, M. M. Acelerômetro eletrônico e a placa Arduíno para ensino de Física em tempo real. Caderno Brasileiro de Ensino de Física, Florianópolis, v. 31, n. 98 1, p. 98-123, abr. 2014.

SÉRÉ, M. G.; COELHO, S. M.; NUNES, A. D. O papel da experimentação no Ensino de Física. Caderno Brasileiro de Ensino de Física, Florianópolis, v. 20, n. 1, p. 30-42, abr. 2003. 
SOUZA, A. R. de; PAIXÃO, A. C.; UZÊDA, D. D.; DIAS, M. A.; DUARTE, S.; AMORIM, H. S. de. A placa Arduino: uma opção de baixo custo para experiências de física assistidas pelo PC. Revista Brasileira de Ensino de Física, v. 33, n. 1, p. 1702, 2011.

\section{Anexo I - Código computacional do experimento (Arduino IDE)}

\section{Cronômetro com Arduino}

Por: Gabryel Silva Ramos [15/10/2013], adaptado de $<$ https://dl.dropboxusercontent.com/u/24142326/Instructables/Cronometro.pdf>.

Uso: Utilizado em experimento de laboratório didático de Física para medir tempo de queda de objetos. Ao longo de um percurso vertical haverá um sensor de início, que terá a função de iniciar a contagem dos tempos, e mais quatro sensores abaixo que irão marcar o tempo gasto em cada percurso. O Arduino então exibirá os tempos de queda em um display LCD.

$* /$

\#include<LiquidCrystal.h>

LiquidCrystallcd(12, 11, 5, 4, 3, 2); // pinos usados pelo LCD neste código

unsigned longinicio, fim1, fim2, fim3, fim4, decorrido; // variáveis usadas em mais de uma função devem ser declaradas

void setup()

\{

lcd.begin(16, 2); // inicializa o LCD (16 caracteres, 2 linhas)

pinMode(6, INPUT); // Define o pino 6 como uma entrada digital.

pinMode(7, INPUT); // Define o pino 7 como entrada digital.

pinMode(8, INPUT); // Define o pino 8 como entrada digital.

pinMode(9, INPUT); // Define o pino 9 como entrada digital.

pinMode(10, INPUT); // Define o pino 10 como entrada digital.

// Introdução

// lcd.setCursor(0,0);

// Posiciona o cursor no primeiro caractere da primeira linha

// Não necessário pois já fica configurado assim em lcd.begin ()

lcd.print(" CRONOMETRO "); // Escreve o que foi solicitado

lcd.setCursor $(0,1)$; // Posiciona o cursor no primeiro caractere da segunda linha

lcd.print("DE QUEDA LIVRE");

delay(5000); // Espera 5 segundos (a função delay() do arduino conta o tempo em milisegundos)

lcd.clear(); // limpa o lcd

// lcd.setCursor( $(0,0)$;

lcd.print("ESPERANDO INICIO");

lcd.setCursor(0,1);

lcd.print("ABANDONAR OBJETO");

\}

Caderno Brasileiro de Ensino de Física, v. 33, n. 2, p. 619-640, ago. 2016. 
void mostrarResultado(float fim)

// Essa função fará toda a matemática para o cálculo do tempo e o escreverá no lcd quando for chamada // Ela pega um dos tempos "fim" gravados e calcula o intervalo de tempo para este

\{

// variáveis (importados do código original)

float h, m, s, ms;

unsigned long resto;

// Cálculos (importados do código original)

decorrido $=$ fim - inicio

$\mathrm{h}=\operatorname{int}($ decorrido $/ 3600000)$;

resto $=$ decorrido $\% 3600000$;

$\mathrm{m}=$ int(resto / 60000);

resto $=$ resto $\% 60000$

$\mathrm{s}=\operatorname{int}($ resto / 1000);

$\mathrm{ms}=$ resto \% 1000;

/* 1cd.setCursor(0,0);

lcd.print("Tempo de queda: "); */

// Mostra os resultados no LCD

lcd.setCursor $(0,1)$;

/*lcd.print(h, 0); // Exibe a variável 'h' (horas)

// O zero representa o número de algarismos depois da virgula. ex: lcd.print(h, 2); mostraria 0,00 lcd.print("h "); // E a letra 'h' depois do resultado // E assim por diante...

lcd.print $(\mathrm{m}, 0)$;

lcd.print("m ");*/

lcd.print(s, 0);

lcd.print("s ");

lcd.print(ms, 0);

lcd.print("ms");

// Obviamente o experimento provavelmente só contará com quedas de poucos segundos.

//Os demais resultados apenas foram importados do código original

\}

void loop() //O funcionamento do cronômetro ocorre aqui.

\{

int sensor 1 , sensor2, sensor3, sensor4, sensor5 ; // declara variáveis

sensor1 = digitalRead (6); // Relaciona 'sensor1' com a entrada digital no pino 6

sensor2 = digitalRead (7); // Relaciona 'sensor2' com a entrada digital no pino 7

sensor3 = digitalRead (8); // Relaciona 'sensor3' com a entrada digital no pino 8

sensor4 = digitalRead (9); // Relaciona 'sensor4' com a entrada digital no pino 9

sensor5 = digitalRead (10); // Relaciona 'sensor5' com a entrada digital no pino 10

int verifica $=0$;

if (sensor1 == LOW) // Se 'sensor1' tem nível lógico 0

\{

inicio = millis(); // Memoriza o tempo de início para o cálculo do tempo de queda delay(15); // para garantir execução do código

lcd.clear();

// lcd.setCursor(0,1); // exibe na linha 1 - não necessário 


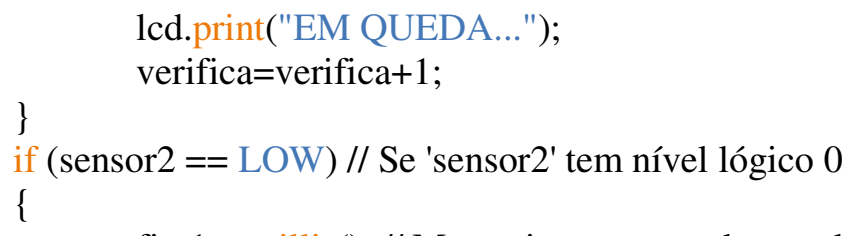

fim1 = millis(); // Memoriza o tempo de parada para o cálculo do tempo de queda //lcd.clear(); delay(15); // para garantir execução do código

// lcd.setCursor(0,0); // não necessário

//mostrarResultado(); // Mostra o resultado no LCD verifica $=$ verifica +1 ;

\}

if (sensor3 == LOW) // Se 'sensor3' tem nível lógico 0

\{

//lcd.clear();

fim2 = millis(); // Memoriza o tempo de parada para o cálculo do tempo de queda delay(15); // para garantir execução do código

// lcd.setCursor(0,0); // não necessário

//mostrarResultado(); // Mostra o resultado no LCD verifica $=$ verifica + ;

\}

if (sensor4 == LOW) // Se 'sensor4' tem nível lógico 0

\{

//lcd.clear();

fim3 = millis(); // Memoriza o tempo de parada para o cálculo do tempo de queda delay(15); // para garantir execução do código

// lcd.setCursor(0,0); // não necessário

//mostrarResultado(); // Mostra o resultado no LCD verifica $=$ verifica +1 ;

\}

if (sensor5 == LOW) // Se 'sensor5' tem nível lógico 0

\{

fim4 = millis(); // Memoriza o tempo de parada para o cálculo do tempo de queda

//lcd.clear(); delay(15); // para garantir execução do código

// lcd.setCursor(0,0); // não necessário

//mostrarResultado(); // Mostra o resultado no LCD verifica $=$ verifica +1 ;

goto exibir;

\}

//Encerra a coleta de dados ao passar pelo ultimo sensor

//Inicia-se a exibição dos dados

if(verifica $==5)\{$

exibir:

delay(1000);

lcd.clear(); // limpa o lcd

// lcd.setCursor $(0,0)$;

lcd.print("DADOS COLETADOS");

lcd.setCursor $(0,1)$;

lcd.print("RESULTADO:");

delay (1500);

//Dados sendo exibidos

repete: 
lcd.clear(); // limpa o lcd

lcd.setCursor $(0,0)$;

lcd.print("Tempo t1: ");

mostrarResultado(fim1); //Calcula e exibe o intervalo de tempo para fim1

delay(5000);

lcd.clear(); // limpa o lcd

lcd.setCursor $(0,0)$;

lcd.print("Tempo t2: ");

mostrarResultado(fim2); //Calcula e exibe o intervalo de tempo para fim2 delay(5000);

lcd.clear(); // limpa o lcd

lcd.setCursor $(0,0)$;

lcd.print("Tempo t3: ");

mostrarResultado(fim3); //Calcula e exibe o intervalo de tempo para fim3

delay(5000);

lcd.clear(); // limpa o lcd

lcd.setCursor $(0,0)$;

lcd.print("Tempo t4: ");

mostrarResultado(fim4); //Calcula e exibe o intervalo de tempo para fim4

delay(5000);

goto repete; 